\title{
Cannibalism or congeneric predation? The African clawed frog, Xenopus laevis (Daudin), preferentially predates on larvae of Cape platannas, Xenopus gilli Rose \& Hewitt
}

\author{
Corey J. Thorp ${ }^{1}$ (i) | James R. Vonesh ${ }^{1,2}$ (i) | John Measey ${ }^{1}$ (i)
}

${ }^{1}$ Centre for Invasion Biology, Department of Botany \& Zoology, Stellenbosch University, Stellenbosch, South Africa

${ }^{2}$ Department of Biology, Virginia Commonwealth University, Richmond, Virginia

\section{Correspondence}

John Measey, Centre for Invasion Biology, Department of Botany \& Zoology,

Stellenbosch University, Stellenbosch, South Africa.

Email: john@measey.com

Funding information

National Research Foundation (NRF) of

South Africa, Grant/Award Number: 87759

\begin{abstract}
Predators are not limited to prey from other species as they can cannibalise vulnerable individuals within their own population. The African clawed frog, Xenopus laevis (Daudin), is a predator with a broad diet, known to consume multiple prey species, including congeners and conspecifics. African clawed frogs occur in sympatry with the Endangered Cape platanna, Xenopus gilli Rose \& Hewitt, which are under threat through competition and predation from $X$. laevis. We investigated the threat of $X$. laevis predation on $X$. gilli using choice and no-choice experiments to evaluate the relative vulnerability of $X$. laevis and $X$. gilli larvae. Results showed that large $X$. gilli larvae had a significantly higher vulnerability to $X$. laevis predation compared to small $X$. gilli larvae. However, the same discrimination was not discerned when offered large and small $X$. laevis larvae, or mixed larvae of the same size. We report ontogenic shifts in behaviour of $X$. gilli larvae that may be a factor in contributing to the vulnerability of large $X$. gilli larvae to adult $X$. leavis predation. Congeneric predation likely has negative implications for the population structure of the Endangered $X$. gilli. Our study underlines the call for the removal of $X$. laevis to conserve populations of $X$. gilli.
\end{abstract}

\section{Résumé}

Les prédateurs ne se limitent pas aux proies d'autres espèces car ils peuvent cannibaliser les individus plus vulnérables de leur propre population. Le xénope lisse Xenopus laevis (Daudin) est un prédateur au régime alimentaire diversifié ;on sait qu'il consomme de nombreuses espèces de proies, dont des congénères et des individus conspécifiques. Les xénopes lisses sont sympatriques de Xenopus gilli Rose \& Hewitt, espèce en danger en raison de la compétition et de la prédation de $X$. laevis. Nous avons étudié la menace de la prédation de ce dernier sur l'autre espèce au moyen d'expériences de choix - non-choix, pour évaluer la vulnérabilité relative des larves des deux espèces. Les résultats montrent que les grands têtards de $X$. gilli avaient une vulnérabilité significativement plus grande à la prédation par X. laevis que les petits têtards. Cependant, nous n'avons pas décelé la même discrimination en cas de présentation de petits et de grands têtards de $X$. laevis, ou de têtards mêlés de même taille. Nous rapportons des modifications ontogéniques de comportement de têtards de $X$. gilli qui peuvent être un facteur contribuant à la vulnérabilité des grands têtards de $X$. gilli face à la prédation 
par les $X$. laevis. La prédation probable des congénères a des implications négatives pour la structure de la population menacée de $X$. gilli. Notre étude conforte l'appel à l'élimination de $X$. laevis dans le but de protéger les populations de $X$. gilli.

\section{KEYWORDS}

cannibalism, predator-prey, size, tadpole, vulnerability

\section{1 | INTRODUCTION}

Xenopus laevis (Daudin), the African clawed frog, is a large pipid ( 130 mm snout-vent length [SVL] in females), and one of the most widespread and common amphibian species found in southern Africa (Measey, 2004). Their adaptability to habitat type and diet has allowed them to move between and exploit permanent and temporary water bodies (Measey et al., 2017), traits which have also made them effective invaders around the world (Measey et al., 2012). They are known to consume other amphibians and are also notorious cannibals that consume both their own eggs and larvae for food even when resources are not limiting (Measey, 1998; Measey et al., 2015; Schoonbee, Prinsloo, \& Nxiweni, 1992). A recent review of diet suggests that cannibalism occurs whenever larval conspecifics are present, apparently independent of other prey availability (Courant et al., 2017).

The Cape platanna, Xenopus gilli Rose \& Hewitt, is a species endemic to the south-western Cape of South Africa. It is significantly smaller ( $60 \mathrm{~mm} \mathrm{SVL}$ in females) than X. laevis (Fogell, Tolley, \& Measey, 2013; Picker \& De Villiers, 1989), but co-occurs at all sites with synchronous breeding (Rau, 1978). Where the two species cooccur, adult $X$. gilli are outnumbered three to one, and recruitment is severely curtailed (de Villiers, Kock, \& Measey, 2016). Competition for resources and predation are currently considered to be direct threats from sympatry with X. laevis (Vogt, Villiers, Ihlow, Rödder, \& Measey, 2017), resulting in its current listing as Endangered by the IUCN (IUCN \& SA-FRoG, 2017). Although predation from adult $X$. laevis on adult $X$. gilli has been observed (Vogt et al., 2017), it may be that predation of more vulnerable life-history stages is more important. However, in these temporary ponds, this impact would be increased if adult $X$. laevis could discriminate between cannibalism of their own larvae and selection of larvae of the sympatric congener, $X$. gilli.

The morphology of $X$. laevis and $X$. gilli larvae is very similar, with minor pigmentation differences at the later stages (Rau, 1978), whereas eggs and newly hatched larvae are indistinguishable (Rau, 1978; personal observation). Although adult $X$. laevis rely on visual cues to detect some terrestrial prey (e.g. Measey, 1998), aquatic prey are thought to be detected by the lateral line organs situated along the trunk and head (Elepfandt, 1996). These organs are extremely sensitive and can be used to detect movement in water. Therefore, differences in activity between X. laevis and X. gilli larvae may influence their relative vulnerability to predation from $X$. laevis predators. Xenopus laevis also use olfactory receptors to detect water-soluble odorants from carrion, but little is known on their ability to detect aquatic prey by means of chemical cues (Freitag, Krieger, Strotmann, \& Breer, 1995)

In this study, we investigated whether $X$. laevis would select cannibalism (on larval X. laevis) or predation (on larval X. gilli) in a system where these two were the only available prey resource. This was tested by analysing the survival rate of $X$. gilli and $X$. laevis larvae in the presence or absence of an X. laevis predator. Behaviour was observed and analysed in order to determine whether larval activity plays a role in vulnerability to $X$. laevis predation.

\section{2 | MATERIALS AND METHODS}

Anecdotal evidence suggests that $X$. laevis larvae are able to reach metamorphosis twice as fast as X. gilli (Rau, 1978) and lay considerably more eggs: $2,700-17,000$ eggs for $X$. laevis compared to $270-$ 400 for X. gilli (de Villiers, 2004; McCoid \& Fritts, 1989; Rau, 1978). Consequently, this may lead to different larvae of each species having different stages of development and/or size at the same age.

\section{1 | Rearing larval prey}

Xenopus laevis adults were captured in the Jonkershoek fish hatchery $\left(-33.9631^{\circ} \mathrm{S} ; 18.9252^{\circ} \mathrm{E}\right)$, and $X$. gilli adults were captured in Kleinmond $\left(-34.3330^{\circ} \mathrm{S} ; 19.0851^{\circ} \mathrm{E}\right)$ using funnel traps baited with chicken liver. Five adult males and females of each species were brought to Stellenbosch University and held in a temperature controlled room set at $16^{\circ} \mathrm{C}$. Passive Integrated Transponder tags (APR 350 , Agrident, Barsinghausen Germany) were injected into adults to allow for identification in order to avoid using the same individuals for breeding in subsequent experiments (de Villiers et al., 2016).

Adults were kept in aquaria $(300 \times 240 \times 240 \mathrm{~mm})$ and were maintained on a diet of chicken livers ad libitum. Frogs not in their reproductive cycle were injected subcutaneously in the dorsal lymph sac with human chorionic gonadotropin (pregnyl) 3 days prior to induced spawning. Once injected, males and females of the same species were placed together as pairs into $(300 \times 240 \times 240 \mathrm{~mm})$ aquaria with a $(15 \mathrm{~mm})$ mesh fitted inside in order to protect the eggs from being eaten by the adults. Xenopus prefer mating when there is minimal disturbance, and spawning took place overnight. Adults were then removed the following morning from the aquaria, leaving the eggs to hatch at a later stage. The resulting larvae were then monitored and fed on Sera Micron (Heinsberg, Germany) daily until the experiment began approximately 14 days after spawning. 
In order to rear larvae to different sizes, different adults were induced at 2-week intervals. Prior to each experiment, larvae were photographed and snout to tail length was measured using ImageJ (Rasband, 2012). Larvae are readily identified to species based on their dorsal pigmentation (Rau, 1978). Adults used for breeding were not used as predators in any experiments. Collection and field work permits were obtained from Cape Nature (AAA007-00159-0056), and ethical clearance was obtained by Stellenbosch University (SU-ACUD15-00011).

\section{2 | Behavioural observation}

Behavioural observations of Xenopus larvae were made for $5 \mathrm{~min}$ per mesocosm, $24 \mathrm{hr}$ prior to each experiment. Xenopus laevis larvae are known to swim continuously in midwater by undulating the posterior portion of their tail at a constant frequency, known as sculling (Hoff \& Wassersug, 1986). Rau (1978) mentioned differences in the behaviour of larvae of $X$. laevis and $X$. gilli, where the latter remain at the bottom of the tank at elevated temperatures. We documented larval movement, as the number of times within 5 min that larvae increased their swimming velocity by using the majority of their tail so as to displace themselves, as opposed to sculling. Position was defined as the proportion of larvae situated within $10 \mathrm{~cm}$ of the bottom and sides of the mesocosm.

\section{3 | Experimental design}

To account for both age and size of the different larval species, the experimental design for this study tested predation from $X$. laevis adults in three different experiments where the prey exposed were (a) same aged larvae of $X$. laevis and X. gilli; (b) different sized larvae of same species (X. laevis); and (c) same size larvae of both species. Each treatment was replicated 4 times $(n=4)$ following the review of Skelly and Kiesecker (2001). We chose to use only female X. laevis as predators in all experiments as we found their appetite to be more consistent than males.

\subsection{1 | Experiment 1: cannibalism and predation of intracohort larvae of Xenopus laevis and Xenopus gilli}

A $2 \times 3$ factorial experimental design was used to examine the effect of X. laevis predation on Xenopus larvae in which predator presence (one $X$. laevis adult female) and prey species (X. laevis and $X$. gilli larvae) were manipulated. Treatments were either presented or withheld from a single $X$. laevis predator during the experiment. Single treatments contained either $X$. laevis or $X$. gilli larvae, whereas mixed treatments contained both $X$. laevis and $X$. gilli larvae in the same mesocosm. Experiments were conducted in individual $\pm 500 \mathrm{~L}$ mesocosms covered with shade cloth (see Thorp, Alexander, Vonesh, \& Measey, 2018). No refuge inside the tanks was provided as Xenopus larvae are all presumed to be midwater suspension feeders (Wassersug, 1996). Mean SVL of adult female $X$. laevis (predators) used in this experiment was $92.3 \mathrm{~mm}$ $(S E= \pm 0.55)$. Predators and treatments were randomly assigned to different mesocosms. Single treatments had 24 larvae of each species, whereas mixed treatments contained densities of 12 for each prey species. Upon rearing, we found that larvae of each species reached a different size at the same age (see Results). Larvae were placed into mesocosms $48 \mathrm{hr}$ prior to experimental trials in order to acclimatise. Predator hunger levels were standardised by starving individuals $48 \mathrm{hr}$ prior to the mesocosm experiment.

The experiment was initiated when predators were introduced into their assigned mesocosms. The experiment proceeded overnight for minimal disturbance (from 18:00 to 08:00 hours) and was completed once the predators were removed $14 \mathrm{hr}$ later. Remaining prey were counted in order to generate data to determine the percentage of surviving larvae for each species.

\subsection{2 | Experiment 2: cannibalism of intercohort larvae of Xenopus laevis}

A second experiment was conducted in order to test whether vulnerability from $X$. laevis predation could be attributed to size. This experiment followed the same procedure as the previous experiments with the exception of using the same larval species at different ages. Therefore, single treatments contained either large or small $X$. laevis larvae, whereas mixed treatments contained both sizes in the same mesocosm. One group of $X$. laevis larvae were reared 4 weeks prior to another group of $X$. laevis larvae. This allowed us to compare the survival of small and large $X$. laevis larvae to $X$. laevis predation. This experiment was not conducted with $X$. gilli as this species is Endangered constraining the number of $X$. gilli adults that we were able to use. Mean length of large $X$. laevis larvae was $26 \mathrm{~mm}(S E= \pm 0.15)$, whereas mean length of small $X$. laevis was $7.5 \mathrm{~mm}(S E= \pm 0.04)$. Mean $S V L$ of predators used in this experiment was $94.8 \mathrm{~mm}(S E= \pm 0.57)$.

\subsection{3 | Experiment 3: cannibalism and predation of intercohort larvae of Xenopus laevis and Xenopus gilli}

A third experiment was conducted to standardise size of the different prey species. This experiment followed the same procedure as Experiment 1 with the exception of rearing $X$. laevis larvae 2 weeks prior to $X$. gilli larvae. This allowed for both larval species to be of the same size once the experiment was conducted. Therefore, single treatments contained either $X$. laevis or X. gilli larvae, whereas mixed treatments contained both $X$. laevis and $X$. gilli larvae in the same mesocosm. Survival of both larval species was measured and compared at the end of the experiment. Xenopus laevis larvae were 2 weeks older than the $X$. gilli larvae. Mean length of $X$. laevis larvae was $20.2 \mathrm{~mm}(S E= \pm 0.12$ ), whereas mean length of $X$. gilli was $19.5 \mathrm{~mm}(S E= \pm 0.10)$. Mean SVL of predators used in this experiment was $94.4 \mathrm{~mm}(S E= \pm 0.42)$.

\subsection{Data analyses}

All experimental and behavioural data were analysed with a ShapiroWilk's test in order to test the normality of the residuals. Experimental 
data were analysed with a factorial ANOVA in order to compare overall differences vulnerability to $X$. laevis predation. If differences were found, a Tukey HSD posthoc analysis was used to determine where the differences lie. Behavioural data were also analysed using a factorial ANOVA and followed with a Tukey HSD in order to test whether there were differences in movement and position between species and/or size. All analyses were conducted using R v3.3.1 (R Core team, 2016).

\section{3 | RESULTS AND DISCUSSION}

\section{1 | Experiment 1}

The first experiment showed that large $X$. gilli larvae were more vulnerable to predation than smaller $X$. laevis larvae of the same age. Contrary to expectation, $X$. gilli larvae grew faster than $X$. laevis and were larger at the beginning of the experiment, even though the adult size is eventually larger in $X$. laevis. Mean length of $X$. gilli larvae was $25 \mathrm{~mm}(S E= \pm 0.13$ ), whereas mean length of $X$. laevis was $9 \mathrm{~mm}$ $(S E= \pm 0.05)$. Survival rates of large $X$. gilli larvae (single $=30.2 \%$, $S E= \pm 0.15$; mixed $=31.2 \%, S E= \pm 0.20$ ) were significantly lower than small $X$. laevis larvae (single $=62.5 \%, S E= \pm 11.79$; mixed $=72.9 \%$, $S E= \pm 9.24)$ for both treatments $\left(F_{1,8}=6.51, p<0.05\right.$; Figure $\left.1 \mathrm{a}\right)$. No mortality was observed in the control treatment.

Xenopus gilli's faster larval development was in contrast to our expectations. Rau (1978) had observed X. gilli larvae to have much slower growth rates than $X$. laevis larvae. This may have been due to Rau (1978) comparing the growth rates of $X$. gilli larvae found in temporary ponds, with fluctuating temperatures, to the growth rates of $X$. laevis larvae reared in a laboratory. Faster larval growth is expected in the temporary water bodies in which in $X$. gilli lives
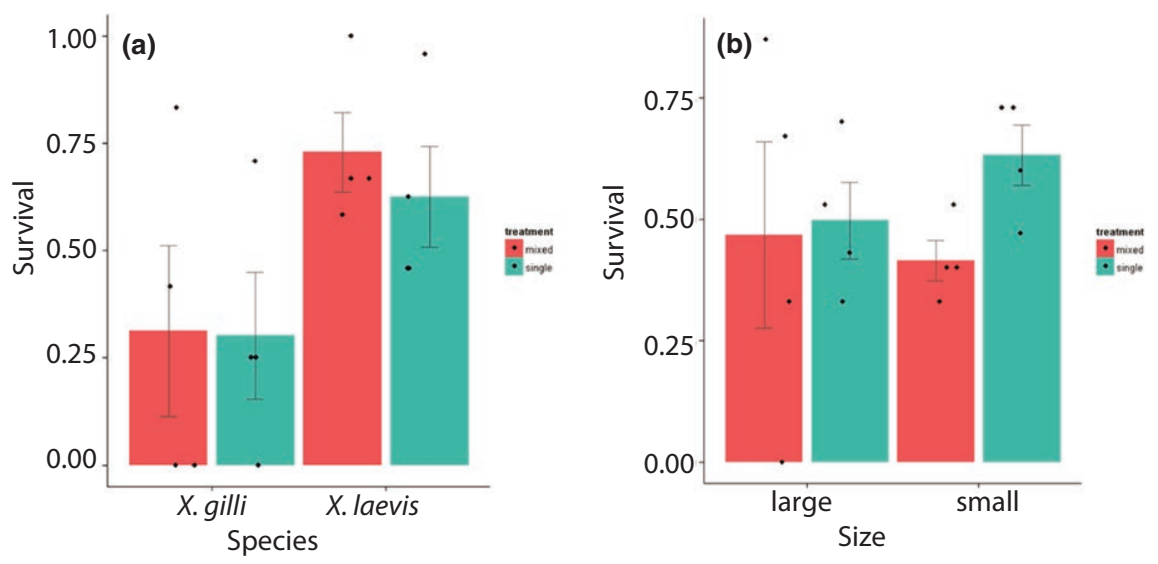

(d)
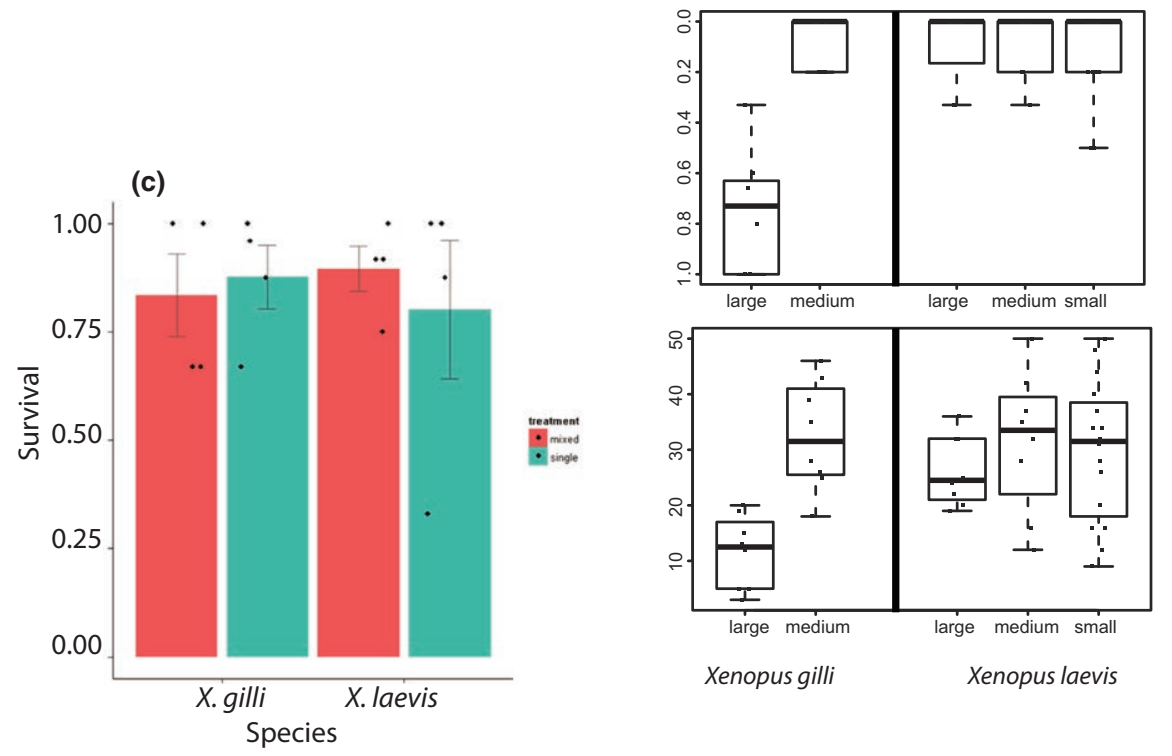

FIGURE 1 (a) Mean survival rates $( \pm S E)$ of large Xenopus gilli and small Xenopus laevis larvae in each treatment exposed to adult $X$. laevis predation. (b) Mean survival rates $( \pm S E$ ) of large $X$. laevis and small $X$. laevis larvae in each treatment exposed to adult $X$. laevis predation. (c) Mean survival rates $( \pm S E)$ of same sized $X$. laevis and X. gilli larvae in each treatment exposed to adult X. laevis predation. (d) Behaviour of Xenopus tadpoles in mesocosms prior to the start of the experiment. (a) The position of different sized Xenopus tadpoles within the mesocosm is presented as a percentage of tadpoles that are more than $10 \mathrm{~cm}$ away from the bottom and sides. (b) The total number of movements made by Xenopus tadpoles within a 5-min period [Colour figure can be viewed at wileyonlinelibrary.com] 
and has been observed elsewhere (Wilbur, 1980; Woodward, 1983). Smaller X. laevis predators would be expected to select smaller Xenopus larvae due to gape limitation. Thus, faster growth rates in $X$. gilli larvae may reduce vulnerability to predation from smaller $X$. laevis predators. It is suggested that predators will select the more dominant prey species in an environment (Wilbur, 1988), and with larger clutch sizes, this may make X. laevis more vulnerable than $X$. gilli.

\subsection{Experiment 2}

In the second experiment, size was not a factor in larval vulnerability, as large and small $X$. laevis larvae had no differences in survival. Large $X$ laevis larvae were 4 weeks older than the small larvae. Survival rate from $X$. laevis predation was not found to be dependent on larval size. There was no significant difference between the survival rates of large $X$. laevis larvae (single $=49.8 \%, S E= \pm 0.08$; mixed $=46.8 \%$, $S E= \pm 0.19)$ and small $X$. laevis larvae (single $=63.25 \%, S E= \pm 0.06$; mixed $=41.5 \%, S E= \pm 0.04)$ for both treatments $\left(F_{1,8}=0.14, p>0.05\right.$; Figure 1b). No mortality was observed for large larvae, while small larvae had $86.7 \%$ survival in the control treatment.

\section{3 | Experiment 3}

The final experiment found that $X$. laevis predators showed no preference or selection towards either species when they were the same size, with no difference in survival between $X$. gilli and X. laevis larvae. Survival rate from $X$. laevis predation was not dependent on species alone. There was no significant difference between the survival rates of $X$. laevis larvae (single $=80.1 \%, S E= \pm 0.16$; mixed $=89.6 \%$, $S E= \pm 0.05$ ) and $X$. gilli (single $=87.6 \%, S E= \pm 0.07$; mixed $=83.5 \%$, $S E= \pm 0.10)$ for either treatments $\left(F_{1,8}=0.01, p>0.05\right.$; Figure $\left.1 c\right)$. No mortality was observed in the control treatment.

No differences in vulnerability between medium X. gilli and $X$. laevis larvae suggest that predators were not able to distinguish between prey species. The observed larval activity and position were similar in both species for medium-sized tadpoles. Xenopus laevis and $X$. gilli larvae were active and swimming in the middle of the water column. This is in contrast to findings in our first experiment where large $X$. gilli larvae were found sculling at the bottom and sides of the mesocosms. Although our results might be a false-negative, they might also be explained by ontogenic behavioural and microhabitat change in $X$. gilli that alter expected predator-prey outcomes, as has been seen in other species (e.g. Alford \& Crump, 1982; Touchon, Jiménez, Abinette, Vonesh, \& Warkentin, 2013). Temporary water bodies might offer a refuge for larvae as they were observed to have a larger density of benthic vegetation and were shallower in comparison with the permanent water bodies in the area.

\section{4 | Behavioural observations}

Across all experiments, large $X$. gilli larvae were significantly different from all other $X$. gilli and $X$. laevis larvae in displacement
$\left(F_{5,42}=5.55, \quad p<0.05\right)$ and position $\left(F_{5,42}=25.57, \quad p<0.05\right)$. Xenopus laevis larvae across all experiments showed similar activity (Figure 1d). No change in behaviour was noted for tadpoles of either species in response to the addition of a predator. The proportion of $X$. laevis larvae found at the bottom and sides of the mesocosms were not significantly different between larvae of different sizes: large (0.089, SE =0.07); medium: $(0.092, S E=0.05)$; small $(0.12, S E=0.05 ; p>0.05$ ). Movement of $X$. laevis larvae was not significantly different between sizes across all experiments: large $(\bar{x}=26.2, S E=2.2)$; medium $(\bar{x}=31.5, S E=4.5)$; small: $(\bar{x}=29.8, S E=3.2 ; p>0.05)$. Xenopus gilli larvae showed differences in locality and activity (Figure $1 \mathrm{~d}$ ). The proportion of $X$. gilli larvae found at the bottom and sides of the mesocosms were significantly different between different sized larvae: large $(0.75$, $S E=0.08)$; medium: $(0.08, S E=0.04 ; p<0.05)$. Large $X$. gilli larvae had significantly less movements compared to their mediumsized conspecifics: large $(\bar{x}=11.5, S E=2.3)$; medium $(\bar{x}=32.5$, $S E=33.4 ; p<0.05)$.

Prey behaviour may have influenced the choice made by adult $X$. laevis predators. Large larvae of $X$. gilli were lower in the water and with reduced movement when compared to all $X$. laevis larvae. Most $X$. gilli larvae were found to be sculling, an antipredatory behaviour that involves the movement of only the posterior portion of the tail to minimise movement (Hoff \& Wassersug, 1986). They were also observed to be situated in the same position as the predators, at the bottom and sides of each mesocosm. This would likely lead to an increase in encounter rate and therefore increase in vulnerability to predation. It has been suggested that larval movement is one of the main factors contributing to vulnerability as movement makes prey more detectable to predators (Caldwell, Thorp, \& Jervey, 1980; Woodward, 1983). Xenopus laevis detect prey in water through movement, via their lateral line organs; therefore, it might be expected that moving larvae should be under increased threat of predation. However, X. laevis larvae were observed to show more movement than $X$. gilli larvae, indicating that adult $X$. laevis may be using the behaviour of the $X$. gilli larvae to distinguish them from $X$. laevis larvae. Our observations on behaviour of large $X$. gilli larvae suggest that they may swim at the bottom of these ponds among the vegetation, without the schooling typically seen in X. laevis (Katz, Potel, \& Wassersug, 1981).

\section{4 | CONCLUSION}

We found some evidence for the ability of $X$. laevis predators to discern between tadpoles of different species (Experiment 1), but not size-matched tadpoles of different species (Experiment 3). Overall, our findings have important implications for the conservation of $X$. gilli. High densities of predators can drastically reduce recruitment success in amphibian prey species (Muedeking \& Heyer, 1976). Xenopus gilli has a limited distribution and therefore cannot escape predation pressure from $X$. laevis in these temporary ponds. In $X$. gilli larvae, fast growth rate to a size that acts as a refuge towards relatively smaller predators; sculling, which reduces 
the chance of detection, and positioning are all mechanisms that may reduce vulnerability to aquatic predators. In addition, the vegetation present in temporary water bodies, together with sculling and positioning, may help protect $X$. gilli larvae from some predation. However, these antipredatory mechanisms were not effective against relatively large $X$. laevis predators in our mesocosms or in field studies (Vogt et al., 2017).

\section{ACKNOWLEDGEMENTS}

We would like to thank members of the MeaseyLab for their help in preparation and harvesting of experiments: Erin Jooste, Ana Nunes, Giovanni Vimercati, Nitya Mohanty, Marike Louw, Mohlamatsane Mokhatla, Alex Rebelo. Permits to catch frogs came from CapeNature (AAA007-00159-0056), and ethics clearance for experiments were granted by Stellenbosch University Research Ethics Committee: Animal Care \& Use (SU-ACUD15-00011).The National Research Foundation (NRF) of South Africa (NRF Grant No. 87759 to GJM) provided financial support.

\section{ORCID}

Corey J. Thorp (iD http://orcid.org/0000-0003-1580-0775

James R. Vonesh (iD http://orcid.org/0000-0003-2481-9988

John Measey iD http://orcid.org/0000-0001-9939-7615

\section{REFERENCES}

Alford, R. A., \& Crump, M. L. (1982). Habitat partitioning among size classes of larval southern leopard frogs, Rana utricularia. Copeia, 1982, 367-373. https://doi.org/10.2307/1444617

Caldwell, J. P., Thorp, J. H., \& Jervey, T. O. (1980). Predator-prey relationships among larval dragonflies, salamanders, and frogs. Oecologia, 46, 285-289. https://doi.org/10.1007/BF00346253

Courant, J., Vogt, S., Marques, R., Measey, J., Secondi, J., Rebelo, R., ... Herrel, A. (2017). Are invasive populations characterized by a broader diet than native populations? PeerJ, 5, e3250. https://doi. org/10.7717/peerj.3250

de Villiers, A. L. (2004). Species account: Xenopus gilli (Rose \& Hewitt, 1927). In L. R. Minter, M. Burger, J. A. Harrison, H. H. Braack, P. J. Bishop \& D. Kloepfer (Eds.), Atlas and red data book of the frogs of South Africa, Lesotho and Swaziland (pp. 260-263). Washington, DC: Smithsonian Institution Press.

de Villiers, F. A., de Kock, M., \& de Measey, G. J. (2016). Controlling the African clawed frog Xenopus laevis to conserve the Cape platanna Xenopus gilli in South Africa. Conservation Evidence, 13, 17.

Elepfandt, A. (1996). Sensory perception and the lateral line system in the clawed frog, Xenopus. In R. C. Tinsley \& H. R. Kobel (Eds.), The biology of Xenopus (pp. 177-193). Oxford, UK: Oxford University Press.

Fogell, D. J., Tolley, K. A., \& Measey, G. J. (2013). Mind the gaps: Investigating the cause of the current range disjunction in the Cape Platanna, Xenopus gilli (Anura: Pipidae). Peer J, 1, e166. https://doi. org $/ 10.7717 /$ peerj.166

Freitag, J., Krieger, J., Strotmann, J., \& Breer, H. (1995). Two classes of olfactory receptors in Xenopus laevis. Neuron, 15, 1383-1392. https:// doi.org/10.1016/0896-6273(95)90016-0
Hoff, K. V. S., \& Wassersug, R. J. (1986). The kinematics of swimming in larvae of the clawed frog, Xenopus laevis. Journal of Experimental Biology, 122, 1-12.

IUCN \& SA-FRoG (2017). Xenopus gilli. The IUCN red list of threatened species 2017: e.T23124A77164368. https://doi.org/10.2305/ IUCN.UK.2017-2.RLTS.T23124A77164368.en. Downloaded on 01 December.

Katz, L. C., Potel, M. J., \& Wassersug, R. J. (1981). Structure and mechanisms of schooling in tadpoles of the clawed frog, Xenopus laevis. Animal Behaviour, 29, 20-33. https://doi.org/10.1016/ S0003-3472(81)80148-0

McCoid, M. J., \& Fritts, T. H. (1989). Growth and fatbody cycles in feral populations of the African clawed frog, Xenopus laevis (Pipidae), in California with comments on reproduction. The Southwestern Naturalist, 34, 499-505. https://doi.org/10.2307/3671508

Measey, G. J. (1998). Diet of feral Xenopus laevis (Daudin) in South Wales, UK. Journal of Zoology, 246, 287-298. https://doi. org/10.1111/j.1469-7998.1998.tb00159.x

Measey, G. J. (2004). Species account: Xenopus laevis (Daudin 1802). In L. R. Minter, M. Burger, J. A. Harrison, H. H. Braack, P. J. Bishop \& D. Kloepfer (Eds.), Atlas and red data book of the frogs of South Africa, Lesotho and Swaziland (pp. 266-267). Washington, DC: Smithsonian Institution Press.

Measey, J., Davies, S., Vimercati, G., Rebelo, A., Schmidt, W., \& Turner, A. A. (2017). Invasive amphibians in southern Africa: A review of invasion pathways. Bothalia-Applied Biodiversity Conservation, 47, a2117. https://doi.org/10.4102/abc.v47i2.2117

Measey, G. J., Rodder, D., Green, S. L., Kobayashi, R., Lillo, F., Lobos, G., ... Thirion, J. M. (2012). Ongoing invasions of the African clawed frog, Xenopus laevis: A global review. Biological Invasions, 14, 2255-2270. https://doi.org/10.1007/s10530-012-0227-8

Measey, G. J., Vimercati, G., de Villiers, F. A., Mokhatla, M. M., Davies, S. J., Edwards, S., \& Altwegg, R. (2015). Frog eat frog: Exploring variables influencing anurophagy. PeerJ, 3, e1204. https://doi. org/10.7717/peerj.1204

Muedeking, M. H., \& Heyer, W. R. (1976). Descriptions of eggs and reproductive patterns of Leptodactylus pentadactylus (Amphibia: Leptodactylidae). Herpetologica, 32, 137-139.

Picker, M. D., \& de Villiers, A. L. (1989). The distribution and conservation status of Xenopus gilli (Anura: Pipidae). Biological Conservation, 49, 169-183. https://doi.org/10.1016/0006-3207(89)90034-7

R Core Team (2016). R: A language and environment for statistical computing. Vienna, Austria: R Foundation for Statistical Computing; 2014.

Rasband, W. S. (2012). ImageJ. Bethesda, MD: US National Institutes of Health. Retrieved from https://imagej.nih.gov/ij/, 1997-2016.

Rau, R. E. (1978). The development of Xenopus gilli Rose \& Hewitt (Anura, Pipidae). Annals of the South African Museum, 76, 247-263.

Schoonbee, H. J., Prinsloo, J. F., \& Nxiweni, J. G. (1992). Observations on the feeding habits of larvae, juvenile and adult stages of the African clawed frog, Xenopus laevis, in impoundments in Transkei. WATER SAPRETORIA, 18, 227-227.

Skelly, D. K., \& Kiesecker, J. M. (2001). Venue and outcome in ecological experiments: Manipulations of larval anurans. Oikos, 94, 198-208. https://doi.org/10.1034/j.1600-0706.2001.t01-1-11105.x

Thorp, C. J., Alexander, M. E., Vonesh, J. R., \& Measey, J. (2018). Sizedependent functional response of Xenopus laevis feeding on mosquito larvae. PeerJ, 6, e5813. https://doi.org/10.7287/peerj. preprints. 26575

Touchon, J. C., Jiménez, R. R., Abinette, S. H., Vonesh, J. R., \& Warkentin, K. M. (2013). Behavioral plasticity mitigates risk across environments and predators during anuran metamorphosis. Oecologia, 173, 801811. https://doi.org/10.1007/s00442-013-2714-8

Vogt, S., de Villiers, F. A., Ihlow, F., Rödder, D., \& Measey, J. (2017). Competition and feeding ecology in two sympatric Xenopus species (Anura: Pipidae). PeerJ, 5, e3130. 
Wassersug, R. (1996). The biology of Xenopus tadpoles. In R. C. Tinsley \& H. R. Kobel (Eds.), The biology of Xenopus: (pp. 195-211). Oxford, UK: Oxford University Press.

Wilbur, H. M. (1980). Complex life cycles. Annual Review of Ecology and Systematics, 11, 67-93. https://doi.org/10.1146/annurev. es.11.110180.000435

Wilbur, H. M. (1988). Interactions between growing predators and growing prey. In B. Ebenman \& L. Persson (Eds.), Size-structured populations (pp. 157-172). Berlin, Heidelberg, Germany: Springer.

Woodward, B. D. (1983). Predator-prey interactions and breeding-pond use of temporary-pond species in a desert anuran community. Ecology, 64, 1549-1555. https://doi.org/10.2307/1937509
How to cite this article: Thorp CJ, Vonesh JR, Measey J. Cannibalism or congeneric predation? The African clawed frog, Xenopus laevis (Daudin), preferentially predates on larvae of Cape platannas, Xenopus gilli Rose \& Hewitt. Afr J Ecol. 2019;57:59-65. https://doi.org/10.1111/aje.12577 